\title{
Women, Work, and Well-Being: \\ The Importance of Work Conditions*
}

\author{
MARY CLARE LENNON
}

Columbia University

Journal of Health and Social Behavior 1994, Vol. 35 (September):235-247

This study investigates the role of work conditions in mediating the effect of employment status on married women's psychological well-being. Employed wives and full-time homemakers are compared on characteristics of their daily work activities and the consequences of these work conditions for psychological well-being. Using data from a national survey of employed wives and homemakers, I find that full-time housework involves more autonomy, more interruptions, greater physical effort, more routine, fewer time pressures, and less responsibility for matters outside one's control than paid work. Differences in work activities between employed wives and homemakers also have direct implications for well-being. Two of the dimensions examined-the extent to which the worker is responsible for things outside her control, and the amount of routine entailed-are associated with greater depressive symptoms among women, regardless of work status. It appears that, as compared to employed wives, full-time homemakers benefit from having less responsibility for things outside their control. Employed wives appear to benefit from having less routinized work than homemakers. As a result of the different configurations of their work characteristics, employed wives and homemakers experience on average similar levels of depressive symptoms.

\section{INTRODUCTION}

Studies of the psychological effects of work for women have tended until recently to focus on broad comparisons of homemakers with employed wives, without directly exam-

\footnotetext{
* This research was supported by NIMH grant MH42974, NSF grant SES-9212586, and the Visiting Scholars' program at the Russell Sage Foundation. I appreciate Melvin Kohn's contribution to the development of the questionnaire and the efforts of Herbert Abelson, Danielle Masursky, and the staff at Response Analysis Corporation in carrying out the survey. I wish to thank Robert K. Merton for his thorough and thoughtful review of this manuscript, Bruce G. Link for his helpful advice, and two anonymous JHSB reviewers for their suggestions. Earlier versions of this paper were presented at the 1993 meeting of the Society for the Study of Social Problems, Miami, Florida, and at the 1993 Work and Mental Health Interim Conference, Sociology of Mental Health Working Group, C.E.U.-Centro Studi per l'Evoluzione Umana and International Sociological Association,
}

ining what these social roles entail. Early studies of the psychological consequences of wives' employment indicated that working outside the home generally benefited women emotionally. For example, employed wives exhibited fewer symptoms of psychological distress than full-time homemakers (e.g., Pearlin 1975; Radloff 1975; Rosenfield 1980). More recent studies, however, report mixed results, with some showing positive effects of employment and others showing no effects (e.g., Barnett and Baruch 1985; Cleary and Mechanic 1983; Gore and Mangione 1983; Horwitz 1982; Kessler and McRae 1982; Lennon and Rosenfield 1992; Nelson and Quick 1985; Rosenfield 1989).

These mixed findings have prompted researchers to examine specific aspects of the lives of employed women more closely, such as their responsibility for family work (e.g.,

Rome, Italy. Address correspondence to: Mary Clare Lennon, Columbia University School of Public Health, 600 West 168th Street, New York, New York 10032. 
Kessler and McRae 1982; Krause and Markides 1985; Lennon, Wasserman, and Allen 1991; Rosenfield 1989; Ross and Mirowsky 1988) and the conditions of their jobs (e.g., Lennon and Rosenfield 1992; Loscosso and Spitze 1990; Lowe and Northcott 1988). These investigations find that an excess of family demands and poor job situations evidently reduce the beneficial effects of employment on wives' well-being.

This accumulating research suggests the importance of going beyond the study of role occupancy per se to investigate the ways in which social roles organize daily life. Being employed or being a homemaker of course entails different configurations of daily activities and working conditions, and these have implications for psychological functioning. Although there has been a good amount of research about the relation of job conditions to well-being, the situation of full-time homemakers has received relatively little attention.

Studies of housework-as-work describe it as entailing physical effort, fragmentation and routine (Berk 1985; Berk and Berk 1979; Ferree 1984; Oakley 1974; Pleck 1985) and, at the same time, as allowing for autonomy and nurturing of others (Andre 1981; DeVault 1991; Hochschild 1989). However, just as the conditions of employment vary among women, so do the conditions of housework. Just as with research on jobs, the investigation of housework-as-work introduces the possibility that particular structural characteristics of the work affect psychological functioning and well-being. Rather than considering homemakers as simply a unidimensional group, we can consider various aspects of homemaking, like aspects of paid work, that may improve or reduce well-being.

The research literature provides little information about the costs and benefits of housework relative to those of other occupations typical of women. Moreover, little attention has been given to the consequences for well-being of differences in work conditions between full-time homemakers and employed wives. Among the studies that use comparable measures of the structural dimensions of paid work and housework (Bird and Ross 1993; Kahn 1991; Kibria et al. 1990; Schooler et al. 1983), only one compares the conditions of work for full-time homemakers and employed women. In making this comparison, Bird and Ross (1993) find that, relative to paid work, housework provides more autonomy, as measured by the opportunity to decide both what work to do and how to do it. They also find housework to be more routine, less intrinsically gratifying, and providing fewer extrinsic rewards. Bird and Ross (1993) also examine the relationship between these work conditions and sense of personal control. They report that routine, and ungratifying and unrewarding work accounts for homemakers' lower sense of personal control relative to employed women. Whether such differences contribute to psychological well-being remains to be investigated. Kohn, Schooler, and colleagues (Kohn and Schooler 1983; Schooler et al. 1983) find that self-directed work-that is, work that allows for the use of initiative and independent judgment, is psychologically beneficial whether it is found on the job or in the home. However, they did not directly compare full-time homemakers to employed wives. The present study offers such a comparison by examining certain characteristics of work among homemakers and employed wives and their relation to psychological well-being.

\section{Work Conditions and Well-Being}

Investigations of the psychological consequences of housework posit a central role for control in the workplace, as do sociological theories and analyses of work generally. A growing body of literature finds control at work to be consequential for psychological functioning and well-being. With the study of various dimensions of control, such as autonomy (Schwalbe 1985), occupational self-direction (Kohn and Schooler 1983; Miller et al. 1979), decision latitude and discretion (Karasek and Theorell 1990), and occupational direction, control, and planning (Link, Lennon, and Dohrenwend 1993), there has emerged a research consensus that lack of control over work activities is detrimental for health, well-being, and self-esteem (see also Frese 1989; Karasek et al. 1988; Lennon and Rosenfield 1992).

In evaluating the distinctive contribution of different dimensions of control, it is especially important to distinguish autonomy from other aspects of control. While the terms "autonomy" and "control" have often been used interchangeably in the literature (see Halaby and Weakleim 1989), as it is used 
here, control encompasses a broader domain, incorporating freedom from close supervision, control over others' work activities, and authority to set organizational policies and procedures. In this study, I focus on autonomy, one of the important dimensions of control. Autonomy entails the opportunity to use discretion in one's work activities. It involves various elements such as freedom of physical movement, freedom to establish plans for one's own task performance and freedom from close supervision (Schwalbe 1985). Autonomy differs from Kohn and Schooler's concept of occupational selfdirection in that the tasks need not be substantively complex or nonroutine in order to permit autonomy in accomplishing them.

Studies of housework find that one of its positive aspects is its allowance for autonomy (Oakley 1974). However, possibilities for autonomy vary. For example, the freedom to set one's own schedule is limited when tasks are time-dependent, as in preparing meals. Oakley (1974) argues that the repetitive nature of most domestic work reduces the housewife's ability to exercise autonomy because, once housewives impose a structure on their work, that structure takes on a life of its own. And Rosenberg (1984) argues that the autonomy of housework involves 'pseudo choices' among consumer goods, but no real decision-making power or control over working conditions. In this regard, the autonomy of housework may resemble the autonomy of certain types of paid jobs typically held by women, such as the secretary's ability to select fonts when preparing envelopes without having control over the content or conditions of work.

While aspects of control over work certainly appear to be central to psychological well-being, control may also have negative correlates. According to Kohn and Schooler (1983), one negative consequence of being able to make decisions about work is the likelihood of being held responsible when things do not work out as planned. Similarly, Blau (1963) has pointed out that anxiety over decision-making is a negative consequence of control at work. Other potential mitigators of the beneficial effects of control are the demands and time pressures that often accompany exercising control at work (Karasek and Theorell 1990).

This investigation examines certain characteristics of employed wives' jobs and home- makers' housework and the consequences of these for a sense of well-being. I hypothesize that full-time homemakers will have more advantageous work conditions than employed wives in terms of greater autonomy, fewer time pressures, and less responsibility for matters outside their control. In contrast, it is assumed that employed wives have more advantageous work conditions in terms of less routinized work, less physically demanding work, and work characterized by fewer interruptions. And, of course, unlike homemakers, employed wives are paid for their work and studies have demonstrated that this income has important implications for psychological well-being (e.g., Rosenfield 1989).

In considering the implications of these differences for psychological well-being, I expect to find, as in recent studies, that there is little difference between employed wives and homemakers. However, I propose that this similarity in average well-being masks an underlying complexity in which employed wives and homemakers are exposed differentially to positive and negative dimensions of work. I hypothesize that the greater autonomy, fewer time pressures, and less responsibility of full-time housework will add to a sense of well-being among housewives, whereas the more interruptions, greater routinization, and lack of pay characteristic of housework will offset these advantages. Among employed wives, it is assumed that psychological well-being will be positively related to the less routine work, fewer interruptions, and payment for work and negatively associated with time pressures and lack of autonomy. Such analyses should help us understand more fully the relation of social roles to psychological well-being by delineating dimensions of those roles that are consequential.

\section{METHODS}

\section{The Sample}

Data for this investigation come from telephone interviews conducted in 1991 with a stratified sample of employed women, employed men, and homemakers, selected to be representative of the U.S. population. Using a sample of randomly-generated telephone numbers, interviewers first determined whether a household member met criteria for inclusion. The sample was restricted to 
persons between the ages of 25 and 54 because these are the ages during which individuals are most actively involved in jobs and household tasks. Since the interview was conducted in English, this meant, of course, that only English-speaking individuals were eligible. The sample of employed women and men was restricted to those who worked 15 hours a week or more for pay, thus insuring that a substantial share of their daily activities would be job-related. As it turned out, employed wives in the sample were almost evenly divided between women in managerial and professional occupations (36\%) and those in technical, sales, and administrative support occupations $(35 \%)$. Seventeen percent were in service occupations and about ten percent were in the remaining Census occupational groupings. ${ }^{1}$

The homemaker sample was restricted to women who were married or living with someone as if they were married, not in school full-time, and not working outside the home more than five hours a week. These restrictions were designed to produce a comparison group of women whose primary work-related activities were focused on homemaking. ${ }^{2}$ The subsample of full-time homemakers was selected to be all female since male homemakers are extremely rare in the general population.

In the screening of households for eligible members, priority was given to locating and interviewing full-time homemakers. When such a homemaker was identified, the probability of her being selected was 80 percent. In the remaining households, an employed individual was selected. Where more than one household member was eligible for the study, the person with the next birthday was included in the sample to ensure random selection (O'Rourke and Blair 1983).

The final sample consists of 300 employed women, 302 employed men, and 202 fulltime homemakers. The response rate for the survey was 67 percent. My analysis focuses on comparisons of homemakers $(\mathrm{N}=202)$ and employed women who were married or living with someone as if they were married $(\mathrm{N}=197)$.

\section{The Measures}

Work Conditions. Measures of work conditions were developed specifically for this study. The conceptualization of many important dimensions of work is based on the work of Kohn, Schooler, and colleagues (Kohn and Schooler 1983; Schooler et al. 1983). Whenever possible, items that met the conceptual definition for a given construct were drawn from the literature and adapted for use in telephone interviews. Priority was given to questions about specific tasks or behaviors, rather than to questions about subjective appraisals, in order to reduce the contamination between the measurement of objective job conditions and psychological outcomes. (See Frese and Zapf [1989] for a discussion of the distinction between subjective and objective self-reports.) Thus, instead of asking respondents whether they feel time-pressured at work, they were asked whether "there is more work than there is time to complete the work."

Six dimensions of work were measured similarly across work setting (i.e., the household and the job): autonomy, time pressure, responsibility for things outside one's control, interruptions, physical effort, and routine. Whenever possible, items were identical in wording except that for employed women they referred to the job and for homemakers they referred to household activities/tasks. Correlational and factor analyses were conducted to assess the comparability of scales for employed wives and homemakers. When subject to within-group factor analyses, the items included in the final version of the scales loaded highly on similar factors. Each scale has adequate within-group reliability. Alpha coefficients for both versions of the questionnaire are given below, along with the wording of the housework questions. Questions about the job appear in Appendix A. Interviewees were asked to choose one of the following four responses to indicate how much each statement resembled their housework/job: very much (coded 4), somewhat (coded 3), only a little (coded 2), or not at all (coded 1), and scales were scored by averaging responses across items. Thus, each scale has a possible range in scores from one to four.

Autonomy is assessed by averaging responses to four items: (1) You decide when to start and when to finish your household activities; (2) You can take breaks whenever you want; (3) You control the speed at which you do your household tasks; and (4) You decide on your own how to go about doing 
the work. The reliability coefficient of these items is .56 for housework and .71 for paid work. Time pressure is measured by the average of three items: (1) You have to work under time pressure; (2) There is more work than there is time to complete the work; and (3) You have enough time to do the work you're supposed to do (reverse scoring). Alpha coefficients are .69 for housework and .76 for paid work. Responsibility for matters outside one's control is assessed by the average of three items: (1) You are held responsible for others' mistakes; (2) You are held responsible when things don't get done; and (3) You are held responsible when things happen even though you can't control them. Alpha coefficients are .76 for housework and .71 for paid work. ${ }^{3}$ Interruptions is measured by the average of three items: (1) You can complete your work without interruptions (reverse scoring); (2) There are distractions that interfere with your household activities; and (3) You are interrupted by other people or telephone calls while doing your tasks. Alpha coefficients are .81 for housework and .72 for paid work. Physical effort is measured by one item: Your household activities require physical effort. Routine work is assessed by the average of four items: (1) Household activities require doing the same thing over and over; (2) You usually know exactly what you'll be doing from one day to the next; (3) You follow the same routine day-in and day-out; and (4) Your household activities involve repetition. Alpha coefficients are .73 for housework and .83 for paid work.

Well-being is assessed by averaging twelve items from the Center for Epidemiologic Studies Depression (CES-D) Scale (Radloff 1977; Ross and Mirowsky 1984). Examples of the items are: you felt lonely; you could not get going; you felt depressed. The time frame for reports of symptoms was the preceding month. Reliability is .88 (coefficient alpha). Scale scores were log transformed to normalize the distribution of the residuals.

Control variables. The analyses control for demographic and family variables that differentiate homemakers and employed wives or correlate with work conditions or depressive symptoms. The demographic variables are age and education (measured in years), race (represented by a dummy variable contrasting Whites with others), and family income, categorized by the midpoint of one of Nine groupings, ranging from less than $\$ 5,000$ to $\$ 100,000$ or more. Other control variables are the number of children living at home and number of hours worked. The latter is number of hours of housework for homemakers and number of hours on the job for employed wives. ${ }^{4}$

Table 1 presents the average values of these control variables separately for employed wives and housewives as well as t-tests assessing the statistical significance of differences between these two groups. The two groups of women differ significantly on education, family income, and number of children at home. On average, homemakers report less education, lower family incomes and more children living at home. Homemakers and employed wives do not differ materially on average age, number of weekly work hours, or race.

\section{RESULTS}

\section{Conditions of Work}

Appendix B provides the correlations of all study variables. The highest correlations

TABLE 1. Sociodemographic Characteristics of Samples of Full-time Homemakers and Employed Wives

\begin{tabular}{|c|c|c|c|}
\hline Variable & $\begin{array}{l}\text { Homemakers } \\
(\mathrm{N}=202) \\
\text { Mean (s.d.) }\end{array}$ & $\begin{array}{c}\text { Employed Wives } \\
(\mathrm{N}=197) \\
\text { Mean (s.d.) }\end{array}$ & t-statistic \\
\hline Age & $38.1(8.2)$ & $38.8(7.9)$ & -.86 \\
\hline Years of Education & $13.0(2.3)$ & $13.9(2.9)$ & $-3.52 * * *$ \\
\hline$\%$ White & $88.1 \%$ & $86.2 \%$ & .57 \\
\hline Family Income & $\$ 41,697(23,787)$ & $\$ 48,369(24,198)$ & $-2.68 * *$ \\
\hline \# of Children at Home & $1.8(1.3)$ & $1.4(1.2)$ & $3.30 * * *$ \\
\hline Work Hours & $38.4(21.4)$ & $37.7(12.1)$ & .38 \\
\hline
\end{tabular}

${ }^{* *} p \leq .01 ; * * * p \leq .001$. 
between measures of work conditions are between time pressure and responsibility for things outside one's control (.36) and time pressure and interruptions (.34). The correlations between other dimensions of work are low-to-moderate. Work status is significantly correlated with each of the measures of work conditions. These associations are portrayed more clearly in Table 2 .

Table 2 compares homemakers and employed wives on conditions of work. It presents two comparisons: tests of the difference between the mean scores ( $t$-statistics) and tests of the difference in the scores' variances (F-ratios). The latter indicate whether the within-group variability is different for homemakers compared to employed wives. If differences in variance exist, then these are taken into account in computing the t-statistic. As described below, comparisons of the variances are substantively interesting as well.

As Table 2 shows, homemakers and employed wives differ on each of the six measures of work conditions. The largest difference is reported for work autonomy. On average, homemakers' autonomy scores (3.79) are nearly one point higher than employed wives' scores (2.81). This is a relatively large difference, inasmuch as the scale scores range from one to four. In fact, 62 percent of homemakers average four on this scale (not shown), indicating that they described their housework "very much" like each of the four elements of autonomy. By way of contrast, only 14 percent of employed wives have an autonomy score of four. Moreover, there is far less variability in reports of autonomy by homemakers; the standard deviation for homemakers is less than half that of employed wives on this measure.
As predicted, employed wives report greater time-pressure and responsibility than homemakers. Both groups score at or below the scale midpoint on these measures, indicating that, on average, neither group experiences excessive time pressures or responsibility in their primary work activity. Scale scores are distributed rather evenly within both groups as reflected in their similar standard deviations.

Homemakers (averaging 3.21) report more interruptions than employed wives (averaging 2.92). Homemakers also describe their work as more physically demanding and more routine than employed wives describe their jobs. There is more variability in employed wives' reports of each of these work conditions than in homemakers' reports.

In summary, housework as a full-time activity is reported to be more autonomous, more subject to interruptions, more physically demanding, and more routine than the average paid job, while paid work involves more time pressures and greater responsibility than housework. And for most work characteristics, homemakers describe a narrower range. This, of course, may result from comparisons of housework and jobs, involving women in a single "occupation" and women in a much wider range of occupations. Compared to the average work situation of employed wives, the profile of work activities for homemakers differs on each of the dimensions examined. These results are largely maintained when controls are introduced for the social and demographic variables listed in Table 1.5 A next step calls for evaluating the consequences of these differences for well-being.

TABLE 2. Work Conditions of Full-time Homemakers and Employed Wives

\begin{tabular}{lllll}
\hline \hline & $\begin{array}{c}\text { Homemakers } \\
(\mathrm{N}=202)\end{array}$ & $\begin{array}{c}\text { Employed Wives } \\
(\mathrm{N}=197)\end{array}$ & t-statistic $^{\mathrm{a}}$ & F-ratio $^{\mathrm{b}}$ \\
Work Conditions & Mean (s.d.) & Mean (s.d.) & $15.54^{* * *}$ & $5.56^{* * *}$ \\
\hline Autonomy & $3.79(.34)$ & $2.81(.82)$ & $-2.73^{* * *}$ & 1.03 \\
Time Pressure & $2.30(.88)$ & $2.54(.87)$ & $-4.25^{* * *}$ & 1.01 \\
Responsibility & $1.90(.90)$ & $2.29(.90)$ & $3.37^{* * *}$ & $1.65^{* * *}$ \\
Interruptions & $3.21(.73)$ & $2.92(.94)$ & $7.77^{* * *}$ & $2.57^{* * *}$ \\
Physical Effort & $3.32(.70)$ & $2.59(1.12)$ & $3.20^{* *}$ & $1.70^{* * *}$ \\
Routine & $3.18(.70)$ & $2.92(.91)$ & & \\
\hline
\end{tabular}

\footnotetext{
${ }^{a}$ t-statistic for difference between mean scores.

${ }^{\mathrm{b}}$ F-ratio for difference between variances.

${ }^{* *} p \leq .01 ; * * * p \leq .001$.
} 


\section{Work Conditions and Depressive Symptoms}

To address the relation of work conditions to well-being, I regressed depressive symptoms on work status and work conditions, with statistical controls for sociodemographic characteristics and work hours. A hierarchical approach was taken in these analyses to evaluate the dimensions of work which were thought to have positive associations with well-being separately from those believed to have negative associations. Table 3 presents the results of these analyses.

The first column of Table 3, (a), shows the zero order association of work status and depressive symptoms. Homemakers report somewhat more symptoms than employed wives $(t=-1.96, p \leq .06)$. As Column (b) indicates, after control variables are introduced, this difference, while reduced somewhat, remains marginally significant $(t=$ $1.65, p \leq .10$ ).

In assessing the relationship of work conditions to depressive symptoms, as a first step I tested for interactions between work conditions and work status (not shown) in order to determine whether the effects of work conditions differ for employed wives and homemakers. None of the six interaction terms turned out to be statistically significant, whether entered alone or as a group. In fact, the six interactions added just one percent to the explained variance, a change that did not approach statistical significance $(F=1.0$, d.f. $=6,353)$. Given these results, only main effects are presented.

To evaluate factors hypothesized to favor homemakers' sense of well-being separately from those hypothesized to have negative associations, selected measures were entered into separate equations. Each equation includes controls for sociodemographic characteristics and work hours. In the final step, all work conditions are added together to assess their net effects.

Results of these analyses appear in Columns (c), (d), and (e) of Table 3. Column (c) shows the effects of those work conditions thought to be favorable to homemakers; i.e., their greater autonomy, lesser time pressure, and lower responsibility for things outside their control. With the introduction of these measures, the effect of work status more than doubles (from .034 to .079), indicating that housewives' depressive symptoms significantly exceed those of employed wives. This appears to result from the lower levels of responsibility for things outside their control among homemakers and the positive association between responsibility and depressive symptoms. In other words, if homemakers were subject to the same levels of responsibility as employed wives, their depressive symptoms would exceed those of employed wives. Neither of the other two work conditions is associated with depressive symptoms.

Column (d) includes those work conditions

TABLE 3. Regression of Depressive Symptoms on Work Status, Work Conditions, and Control Variables $(\mathbf{N}=354)$

\begin{tabular}{|c|c|c|c|c|c|c|c|c|c|c|}
\hline \multirow[b]{2}{*}{ Variable } & \multicolumn{2}{|r|}{ (a) } & \multicolumn{2}{|c|}{ (b) } & \multicolumn{2}{|l|}{ (c) } & \multicolumn{2}{|l|}{ (d) } & \multicolumn{2}{|l|}{ (e) } \\
\hline & b & s.e. (b) & $\mathrm{b}$ & s.e. (b) & b & s.e. (b) & b & s.e. (b) & b & s.e. (b) \\
\hline \multicolumn{11}{|l|}{ Work Status } \\
\hline$($ Homemaker $=1)$ & $.039^{+}$ & $(.021)$ & $.034^{+}$ & $(.021)$ & $.079 * *$ & $(.027)$ & .013 & $(.023)$ & $.057 *$ & $(.029)$ \\
\hline \multicolumn{11}{|l|}{ Control Variables: } \\
\hline Age & & & $-.005 * * *$ & $(.001)$ & $-.005 * * *$ & $(.001)$ & $-.005 * * *$ & $(.001)$ & $-.005 * * *$ & $(.001)$ \\
\hline Years of Education & & & $-.008^{\dagger}$ & $(.004)$ & $-.008^{+}$ & $(.004)$ & -.005 & $(.004)$ & -.006 & $(.004)$ \\
\hline Race $($ White $=1$ ) & & & $-.069 *$ & $(.031)$ & $-.063^{*}$ & $(.030)$ & $-.070^{*}$ & $(.031)$ & $-.059^{+}$ & $(.030)$ \\
\hline Family Income & & & $-.001^{*}$ & $(.000)$ & $-.001^{*}$ & $(.000)$ & $-.001^{+}$ & $(.000)$ & $-.001^{+}$ & $(.000)$ \\
\hline \# of Children at Home & & & $-.027 * *$ & $(.008)$ & $-.030 * * *$ & $(.008)$ & $-.029 * * *$ & $(.008)$ & $-.031 * * *$ & $(.008)$ \\
\hline Work Hours & & & .000 & $(.001)$ & .000 & $(.001)$ & .000 & $(.000)$ & -.000 & $(.000)$ \\
\hline \multicolumn{11}{|l|}{ Work Conditions: } \\
\hline Autonomy & & & & & -.025 & $(.017)$ & & & -.017 & $(.017)$ \\
\hline Time Pressure & & & & & .010 & $(.013)$ & & & .015 & $(.013)$ \\
\hline Responsibility & & & & & $.041^{* * *}$ & $(.012)$ & & & $.039 * * *$ & $(.012)$ \\
\hline Interruptions & & & & & & & -.002 & $(.013)$ & -.014 & $(.013)$ \\
\hline Physical Effort & & & & & & & $.026 *$ & $(.011)$ & .019 & $(.011)$ \\
\hline Routine & & & & & & & $.028 *$ & $(.014)$ & $.029 *$ & $(.013)$ \\
\hline $\mathrm{R}^{2}$ & .009 & & .128 & & .171 & & .155 & & .196 & \\
\hline
\end{tabular}

${ }^{\dagger} p \leq .10 ;{ }^{*} p \leq .05{ }^{* *} p \leq .01 ;{ }^{* * *} p \leq .001$. 
thought to favor employed wives' well-being; i.e., their fewer interruptions, less physical effort, and less routine work. With these controls, the effect of work status is reduced to insignificance. Both work requiring physical effort and routine work are associated with greater depressive symptoms. Thus, if jobs were as routine and physically demanding as housework, employed wives would resemble homemakers in their level of depressive symptoms.

The final column, (e), considers the simultaneous effects of the six work conditions. As shown in the first row, the net effect of work status is positive, indicating that homemakers' depressive symptoms exceed those of employed wives once differences in their work situations are adjusted. With all work conditions included in the equation, the effect of physical effort is reduced to insignificance. The effects of routine work and responsibility for things outside one's control remain significant and positively related to depressive symptoms. Because the work scales are measured on the same metric, it is possible to compare the unstandardized regression coefficients. Doing so, we find that the effect of responsibility is somewhat stronger than the effect of routine $(b=.039$ for responsibility vs. .029 for routine). If their work environment entailed as much responsibility as paid work, homemakers would exhibit greater levels of depressive symptoms compared to employed wives. This holds in spite of the greater amount of routine work experienced by homemakers and the positive association of routine work with depressive symptoms. ${ }^{6}$

A further analysis (not shown) explored the relationship of the contribution to family income by employed wives to depressive symptoms. An indicator of the percent of income earned by the wife was added to the variables listed in Column (e) of Table 3. Work status was excluded from the equation, which was estimated for employed wives only. This analysis indicated that wives' income does not contribute independently to depressive symptoms after work conditions are controlled. However, when work conditions (which are correlated with wives' earnings) are excluded from the equation, wives' relative earnings show a marginally significant negative association with symptoms $(b=-.097$, s.e. $=.058 ; p \leq .10)$.

To summarize, differences in the work environments of employed wives and homemakers have implications for their well-being. On average, employed wives and homemakers differ only marginally on depressive symptoms. However, these symptom levels appear to derive from the different patterns of work conditions that characterize housework and paid work. A relatively high degree of responsibility for things outside one's own control, more characteristic of paid work than housework, is associated with greater levels of depressive symptoms. And a relatively high degree of routine work, more characteristic of housework than paid work, is associated with greater depressive symptoms. The net result of these different inputs is an average similarity in symptom levels for employed wives and housewives.

\section{DISCUSSION AND CONCLUSIONS}

From these results, it appears that many of the activities and conditions encountered daily by employed wives and by homemakers differ. The average full-time homemaker reports that her work involves more autonomy, more interruptions, greater physical effort, more routine, fewer time pressures, and less responsibility than the average employed wife reports. Full-time housework does not vary as much as paid work in the amount of autonomy, physical effort, interruptions, and routine it entails.

These differences in work activities between employed wives and homemakers have implications for well-being. Two of the dimensions examined-the extent to which the worker is responsible for things outside her control and the amount of routine her work involves-are associated with greater depressive symptoms among women, regardless of work status. Compared to employed wives, homemakers obtain a certain benefit for having less responsibility. And, compared to homemakers, employed wives appear to benefit from less routine at work. On balance, as a result of these distinctive work configurations, employed wives and homemakers exhibit similar levels of depressive symptoms.

The data do not support the hypothesis that autonomy is associated with lower levels of depressive symptoms. As noted earlier, autonomy is operationalized in this study as discretion over work activities. It involves the 
freedom to determine how to accomplish tasks - for example, deciding when to start work or how fast to work. Unlike Kohn and Schooler's concept of self-direction, which entails the exercise of initiative and judgment to accomplish work tasks, autonomy may exist even when tasks are routine or explicitly set forth (Schwalbe 1985). Since many of the activities that characterize women's housework or jobs are repetitive and routine, the exercise of autonomy may not provide enough control over work processes to improve psychological well-being.

The findings with respect to responsibility and routine can be interpreted as evidence that other aspects of control over work are related to psychological well-being. The items measuring responsibility include responsibility for others' mistakes, responsibility when things do not get done, and responsibility for things one cannot control. It appears that such responsibility derives from having to meet demands that are not within the worker's power to accomplish on her own. It is likely that working under these conditions generates the experience of a lack of control over work outcomes and, in turn, gives rise to greater depressive symptoms. This interpretation is consistent with Rosenfield's (1989) view that excessive demands and low levels of actual control or power affect psychological wellbeing by reducing individuals' sense that the course of their lives is within their control.

The finding that routine work is associated with depressive symptoms supports Kohn and Schooler's view that work which allows for self-direction benefits psychological functioning. Nonroutine work is a requirement of occupational self-direction, along with substantive complexity and freedom from close supervision. ${ }^{7}$ Thus, excessively routinized work minimizes opportunities for control over work activities, and the absence of selfdirection reduces psychological well-being. Bird and Ross (1993) report similar results for the relation of routine work to low levels of personal control.

In considering these interpretations further, it is important to point out some limitations of this study. The response rate of 67 percent means that one-third of potentially eligible individuals did not participate in the study. Should these individuals differ substantially from those in the sample, then the parameter estimates may be biased. An additional limitation of this study is its cross-sectional design. It is possible that women's choice of housework or paid work derives from certain of their distinctive characteristics. For example, some women may opt for full-time housework because they prefer work that involves less time pressure or more autonomy. While the general issue of selection into employment merits further study, Gerson (1985) suggests that women's choice between employment and homemaking is not simply based on their personal characteristics or early socialization.

The cross-sectional nature of these data also make inferences about well-being open to question. It is possible that women with high levels of depressive symptoms report their work situations as more routine and see themselves as having greater responsibility for things outside their control. In support of the causal direction implied here - that is, that work conditions contribute to depressive symptoms - other investigators have provided some evidence based on longitudinal research on occupations in male samples (e.g., Kohn and Schooler 1982). Nevertheless, it remains for future research to investigate issues of causal direction using prospective data on employed wives and homemakers.

This investigation underscores the importance of specifying the ways in which social positions structure the content of daily life. Social positions are not simply categorical identities or roles; they shape the day-to-day experiences and challenges encountered by individuals. This day-in and day-out exposure to life circumstances, in turn, influences psychological well-being and functioning. Thus, by uncovering some of the complexity underlying women's social roles, this study increases our understanding of the relation of these roles to psychological well-being.

\section{NOTES}

1. This distribution differs somewhat from the representation of women in the U.S. labor force. According the Bureau of Labor Statistics (U.S. Department of Labor 1994), in 1992, 27 percent of all women aged 16 and older were in managerial and professional occupations, 44 percent held technical, sales, and administrative support occupations, 18 percent were in service occupations, and the remaining 11 percent were in the following three categories: precision production, craft, and repair; operators, fabricators, and laborers; and farming, forestry, and fishing occupations. Since my sample is 
restricted in age, marital status, and hours employed, it is not directly comparable to this overall distribution.

2. Given the fact that employed wives also spend a substantial amount of time on housework (mean hours $=23.4$ ), all equations were estimated using a group of employed wives restricted to those who spend more time on the job than on housework. Because results of these analyses are essentially the same as those appearing in Tables 2 and 3, the analyses reported are based on all employed wives.

3. An anonymous reviewer suggested that responsibility for things outside one's control may have less to do with the nature of work and more to do with the nature of one's relationships with others. While it is clear that such responsibility has to do with relationships with others, the nature of these relationships derives, in part, from the structure of the work relations. This is seen most clearly among employed wives, where responsibility for matters outside one's control is significantly correlated with a scale measuring control over the work of others $(r=.44)$ and with an item measuring complexity of work with people $(r=.32)$. These correlations suggest that responsibility for matters outside one's control for employed wives is based, to some extent, on the nature of their work. Among homemakers, there is no clear equivalent of these dimensions of work. Because the domain of responsibility for homemakers has to do with housework and children, I examined correlations of these factors with responsibility for matters outside one's control. Such responsibility shows a small but significant correlation with the number of school-aged children $(r=.14)$ and a marginally significant association with the amount of time the respondent spends on housework, relative to time spent by others $(r$ $=.12, p<.10)$. These correlations suggest that responsibility for matters outside one's control is, at least to some extent, related to the nature of the housework.
4. Other measures of work hours were considered for employed wives to take into account their time spent on housework. I summed the total number of hours spent each week on housework and on paid work and used this sum in the analyses instead of hours on the job. The results of these analyses mirror those obtained when hours of paid work is used as the indicator of hours worked.

5. Because these differences could be due to differences between employed wives and homemakers on social and family variables, I regressed each work condition on work status, controlling for age, education, race, family income, number of children at home, and work hours. The differences between employed wives and homemakers remain statistically significant, with one exception. The association between work status and routine is reduced to a marginal level of statistical significance $(t=$ $1.7, p<.10)$.

6. One anonymous reviewer suggested that another way of looking at this relationship is to examine the direct and indirect effects of work status on depressive symptoms. Doing so entails setting up a path model in which work status influences work conditions and work conditions, in turn, influence symptoms. In this model, with sociodemographic variables controlled, the direct effect of work status on depressive symptoms is .143 (standardized regression coefficient associated with Equation (e) in Table 3). The sum of the indirect effects of work status on symptoms (through each of the six dimensions of work) is -.038 . This indicates that work conditions suppress the association between work status and depressive symptoms to some extent, masking the higher symptom levels of homemakers. The path model is available, upon request, from the author.

7. These aspects of occupational self-direction could not be measured comparably for jobs and housework and are not considered in this investigation. 


\section{APPENDIX A. \\ Measures of Job Conditions}

Autonomy

You decide when to come to work and when to leave.

Your can take breaks whenever you want.

You control the speed at which you work.

Your decide on your own how to go about doing the work.

Time Pressure

You have to work under time pressure.

There is more work than there is time to complete the work.

You have enough time to do the work you are supposed to do (reverse scoring).

Responsibility

You are held responsible for others' mistakes.

You are held responsible when things don't get done.

Interruptions

You are held responsible when things happen at work even though you can't control them.

Physical Effort

You can complete your work without interruptions. (reverse scoring)

There are distractions that interfere with the work.

You are interrupted by other people or telephone calls while doing your job.

Routine

The job requires physical effort.

The job requires doing the same thing over and over.

You usually know exactly what you'll be doing from one day to the next.

You follow the same routine day-in and day-out.

The job involves repetition.

\section{APPENDIX B. \\ Correlation Matrix of Study Variables ${ }^{a}$}

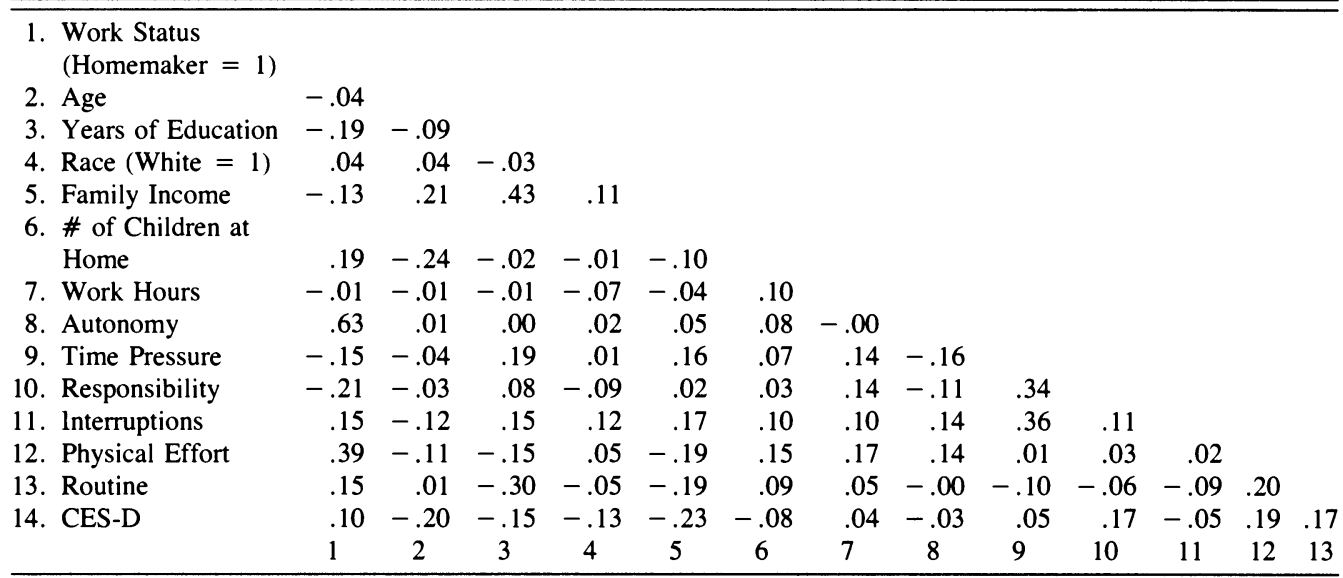

${ }^{\text {a }}$ Correlations $\geq .11$ are significant at $p \leq .05$ (two-tailed).

\section{REFERENCES}

Andre, Rae. 1981. Homemakers: The Forgotten Workers. Chicago: University of Chicago Press.

Barnett, Rosalind C. and Grace K. Baruch. 1985. "Women's Involvement in Multiple Roles and Psychological Distress." Journal of Personality and Social Psychology 49:135-45.

Berk, Richard A. and Sarah Fenstermaker Berk. 1979. Labor and Leisure at Home: Content and Organization of the Hausehold Day. Beverly Hills, CA: Sage.

Berk, Sarah Fenstermaker. 1985. The Gender
Factory: The Apportionment of Work in American Households. New York: Plenum.

Bird, Chloe E. and Catherine E. Ross. 1993. "Houseworkers and Paid Workers: Qualities of the Work and Effects on Personal Control." Journal of Marriage and the Family 55:913-25. Blau, Peter M. 1963. The Dynamics of Bureaucracy. Chicago: University of Chicago Press.

Cleary, Paul and David Mechanic. 1983. "Sex Differences in Psychological Distress among Married People." Journal of Health and Social Behavior 24:111-21. 
DeVault, Marjorie. 1991. Feeding the Family: The Social Organization of Caring as Gendered Work. Chicago: University of Chicago Press.

Ferree, Myra Marx. 1984. "Class, Housework, and Happiness: Women's Work and Life Satisfaction." Sex Roles 11:1057-74.

Frese, Michael. 1989. "Theoretical Models of Control and Health." Pp. 107-28 in Job Control and Worker Health, edited by S.L. Sauter, J.J. Hurrell, Jr., and C.L. Cooper. New York: Wiley and Sons.

and Dieter Zapf. 1989. "Methodological Issues in the Study of Work Stress: Objective vs. Subjective Measurement of Work Stress and the Question of Longitudinal Studies." Pp. 375411 in Causes, Coping and Consequences of Stress at Work, edited by C. L. Cooper and R. Payne. New York: Wiley and Sons.

Gerson, Kathleen. 1985. Hard Choices: How Women Decide about Work, Career, and Motherhood. Berkeley, California: University of California Press.

Gore, Susan and Thomas W. Mangione. 1983. "Social Roles, Sex Roles, and Psychological Distress: Additive and Interactive Models of Sex Differences." Journal of Health and Social Behavior 24:300-312.

Halaby, Charles N. and David L. Weakliem. 1989. "Worker Control and Attachment to the Firm." American Journal of Sociology 95:549-91.

Hochschild, Arlie with Anne Machung. 1989. The Second Shift: Working Parents and the Revolution at Home. New York: Academic Press.

Horwitz, Allan V. 1982. "Sex Role Expectations, Power, and Psychological Distress." Sex Roles 8:607-23.

Kahn, Robert L. 1991. "The Forms of Women's Work." Pp. 65-83 in Women, Work, and Health, edited by M. Frankenhaeuser, U. Lundberg, and M. Chesney. New York: Plenum.

Karasek, Robert and Töres Theorell. 1990. Healthy Work: Stress, Productivity, and the Reconstruction of Working Life. New York: Basic.

Töres Theorell, Joseph Schwartz, Peter Schnall, Carl Pieper, and John Michela. 1988. "Job Characteristics in Relation to the Prevalence of Myocardial Infarction in the U.S. HES and HANES." American Journal of Public Health 78:910-18.

Kessler, Ronald C. and James E. McRae, Jr. 1982. "The Effects of Wives' Employment on the Mental Health of Married Men and Women." American Sociological Review 47:216-27.

Kibria, Nazli, Rosalind C. Barnett, Grace K. Baruch, Nancy L. Marshall, and Joseph H. Pleck. 1990. "Homemaking-role Quality and the Psychological Well-Being and Distress of Married Women." Sex Roles 22:327-47.

Kohn, Melvin L. and Carmi Schooler. 1982. "Job
Conditions and Personality: A Longitudinal Assessment of Their Reciprocal Effects." American Journal of Sociology 87:1257-86.

and Carmi Schooler (Eds.). 1983. Work and Personality: An Inquiry into the Impact of Social Stratification. Norwood, NJ: Ablex Publishing.

Krause, Neal and Kyriakos S. Markides. 1985. "Employment and Well-Being in Mexican American Women." Journal of Health and Social Behavior 26:15-26.

Lennon, Mary Clare and Sarah Rosenfield. 1992. "Women and Mental Health: The Interaction of Job and Family Conditions." Journal of Health and Social Behavior 33:316-27.

, Gail A. Wasserman, and Rhianon Allen.

1991. "Husbands' Involvement in Child Care and Depressive Symptoms Among Mothers of Infants." Women \& Health 17:1-23.

Link, Bruce G., Mary Clare Lennon, and Bruce P. Dohrenwend. 1993. "Socioeconomic Status and Depression: The Role of Occupations Involving Direction, Control, and Planning." American Journal of Sociology 98:1351-87.

Loscosso, Karyn A. and Glenna Spitze. 1990. "Working Conditions, Social Support, and the Well-Being of Female and Male Factory Workers." Journal of Health and Social Behavior 31:313-27.

Lowe, Graham S. and Herbert C. Northcott. 1988. "The Impact of Working Conditions, Social Roles, and Personal Characteristics on Gender Differences in Distress." Work and Occupations 15:55-77.

Miller, Joanne, Carmi Schooler, Melvin L. Kohn, and Karen A. Miller. 1979. "Women and Work: The Psychological Effects of Occupational Conditions." American Journal of Sociology 85:66-94.

Nelson, Debra L. and James Campbell Quick. 1985. "Professional Women: Are Distress and Disease Inevitable?" Academy of Management Review 10:206-13.

Oakley, Ann. 1974. The Sociology of Housework. New York: Pantheon.

O'Rourke, Diane and Johnny Blair. 1983. "Improving Random Selection in Telephone Surveys." Journal of Marketing Research 20:42832.

Pearlin, Leonard I. 1975. "Sex Roles and Depression." Pp. 191-207 in Life-span Developmental Psychology: Normative Life Crises, edited by N. Datan and L. H. Ginsberg. New York: Academic Press.

Pleck, Joseph H. 1985. Working Wives/Working Husbands. Beverly Hills, CA: Sage.

1975. "Sex Differences in Depression: The Effects of Occupation and Marital Status." Sex Roles 1:249-65.

Radloff, Leonore S. 1977. “The CES-D Scale: A Self-report Depression Scale for Research in the 
General Population." Applied Psychological Measurement 1:385-401.

Rosenberg, Harriet G. 1984. "The Home is the Workplace: Hazards, Stress, and Pollutants in the Household." Pp. 219-45 in Double Exposure: Women's Health Hazards on the Job and at Home, edited by W. Chavkin. New York: Monthly Review Press.

Rosenfield, Sarah. 1980. "Sex Differences in Depression: Do Women Always Have Higher Rates?" Journal of Health and Social Behavior 21:33-42.

1989. "The Effects of Women's Employment: Personal Control and Sex Differences in Mental Health. Journal of Health and Social Behavior, 30:77-91.

Ross, Catherine E. and John Mirowsky. 1984. "Components of Depressed Mood in Married Men and Women: The Center for Epidemiolog- ical Studies Depression Scale." American Journal of Epidemiology 119:997-1004. and John Mirowsky. 1988. "Child Care and Emotional Adjustment to Wives' Employment." Journal of Health and Social Behavior 29:127-38.

Schooler, Carmi, Melvin L. Kohn, Karen A. Miller, and Joanne Miller. 1983. "Housework as Work." Pp. 242-60 in Work and Personality: An Inquiry into the Impact of Social Stratification, edited by M.L. Kohn and C. Schooler. Norwood, NJ: Ablex.

Schwalbe, Michael L. 1985. "Autonomy in Work and Self-esteem." The Sociological Quarterly 26:519-35.

U.S. Department of Labor. 1994. Employment and Earnings. Bureau of Labor Statistics, January. Washington, DC: U.S. Government Printing Office.

Mary Clare Lennon is assistant professor at Columbia University School of Public Health (Sociomedical Sciences). Her research focuses on the relation of gender to the conditions of paid and unpaid work, and on the implications of this relation for psychological well-being. 